\title{
Platelet to lymphocyte and neutrophil to lymphocyte ratios as strong predictors of mortality in intensive care population
}

\section{SUMMARY}

OBJECTIVE: Patients in intensive care units (ICU) have greater morbidity and mortality. We aimed to study neutrophil to lymphocyte ratio (NLR) and platelet to lymphocyte ratio $(P L R)$ in the ICU population.

METHODS: Medical and laboratory data of patients treated in ICU were retrospectively analyzed. Patients were divided into deceased and survived groups.

RESULTS: The NLR of survived and deceased groups were 3.6 (0.2-31) and 9.5 (1-40), respectively ( $p<0.001)$. The PLR of the survived group (111 [16-537]) was significantly lower than the PLR of the deceased (209 [52-1143]), ( $p<0.001)$. An NLR higher than 4.9 had $84 \%$ sensitivity and 67\% specificity is selecting deceased patients (AUC:0.80, $p<0.001$ ). A PLR higher than 112 had $83 \%$ sensitivity and $52 \%$ specificity in predicting deadly cases (AUC:0.76, p<0.001). Both PLR and NLR were significantly and positively correlated with creactive protein levels.

CONCLUSION: We suggest that physicians should pay particular attention to the treatment of patients in ICU with elevated NLR and $P L R$.

KEYWORDS: Critical care. Neutrophils. Lymphocytes. Blood platelets. Mortality.

\section{INTRODUCTION}

Patients with organ dysfunction and failure, subjects that need to be followed-up closely, and patients who need urgent treatment usually require treatment in Intensive Care Units (ICU). Since mortality and morbidity rates are much higher in the ICU population compared to other patients who do not require treatment in ICU, surrogate markers for predicting mortality in ICU subjects have been established. C-reactive protein (CRP) is one of these markers and usually increases in conditions associated with inflammation or infection'.

The utility of hemogram-derived inflammatory markers is on the rise recently. Several of hemogram markers have been suggested to be related to inflammatory situations and outcomes in the literature ${ }^{2-5}$. 
Neutrophil to lymphocyte ratio (NLR) and platelet to lymphocyte ratio (PLR) are two novel markers reproduced from routine hemogram tests. The association between NLR and inflammatory conditions is reported in a recent study ${ }^{6}$. Moreover, Salciccioli et al. ${ }^{7}$ proposed that NLR was related to the outcomes of critically ill subjects. Similarly, PLR was also regarded as a prognostic and inflammatory predictor in the ICU population $^{8}$. However, further studies are needed to confirm the association between mortality and these markers and investigate the possible correlation between CRP and PLR and NLR.

In the present retrospective study, we aimed to compare the NLR and PLR values of deceased ICU subjects with those of patients who survived. We also aimed to find out whether PLR and NLR were correlated to the CRP.

\section{METHODS}

The medical records of patients treated in the intensive care unit of our institution between April 2017 and January 2018, were enrolled in the study. An approval of institutional directorate was obtained. The data of the subjects were recorded from an institutional computerized database and patient files. Pregnant patients, subjects with known hematologic disorders, on treatment that may interfere with platelet functions, and older than 18 years were excluded from the study. Patients were grouped into two groups according to the outcome, survived or deceased.

Age, gender, reason for ICU admission, duration of intensive care treatment, and laboratory parameters, including, white blood cell count (WBC), neutrophil count (neu), lymphocyte count (lym), hemoglobin ( $\mathrm{Hb})$, hematocrit $(\mathrm{Htc})$, platelet count (plt), and c-reactive protein (cRP) were recorded. The NLR was calculated by merely dividing the neu by the lym, and PLR was calculated by dividing the plt by the lym.

Statistical analysis was done using SPSS software (SPSS 10.0 for Windows, IBM Inc., Chicago, Il, USA). Kolmogorov- Smirnov test was conducted to observe the distribution of parameters in the study groups. Homogenous variables were analyzed by independent samples t-test and expressed as mean $+/$ - Standard Deviation, while non-homogenous variables were analyzed by Mann Whitney $\mathrm{U}$ test and expressed as median (min-max). Chi- square test was used to analyze categorical variables. The correlation between variables were conducted by Pearson's correlation analyze test. A ROC analysis was performed to define the cut off values of CRP, NLR, and PLR in predicting mortality. Statistical significance was set on a p-value lower than 0.05 .

\section{RESULTS}

A total of 172 subjects were enrolled in the study; 95 in the survived group and 77 in the deceased. The mean age of the survived group was $63.3 \pm 20.4$ years and $71.5 \pm 14.5$ in the deceased group. Subjects in the deceased group were significantly older than those in the survived group $(\mathrm{p}=0.003)$. There were 41 women and 51 men in the survived group and 32 women and 45 men in the deceased. Gender was not significantly different between the survived and deceased groups $(\mathrm{p}=0.83)$.

Treatment durations in the intensive care unit for patients in the survived and deceased groups were 3 (1-118) and 6 (0-97) days, respectively. The difference was statistically significant $(\mathrm{p}=0.003)$.

Levels of WBC, plt, and plasma glucose were not significantly different between study groups ( $p>0.05$ for all). Serum CRP $(p<0.001)$ was significantly higher and $\mathrm{Hb}(p=0.02)$ and Htc $(p=0.02)$, were significantly lower in the deceased group compared with the survived group.

The NLR of survived and deceased subjects were 3.6 (0.2-31) and 9.5 (1-40), respectively. NLR was significantly higher in the deceased group compared with the survived $(p<0.001)$. The PLR of the survived group (111 [16-537]) was significantly lower than the PLR of the deceased group (209 [52-1143]), $(\mathrm{p}<0.001)$.

The ROC analysis revealed that a CRP higher than $51.5 \mathrm{mg} / \mathrm{dl}$ had $84 \%$ sensitivity and $57 \%$ specificity in predicting mortality (AUC:0.76, $\mathrm{p}<0.001$ ). An NLR higher than 4.9 had 84\% sensitivity and 67\% specificity in selecting deceased patients (AUC:0.80, $\mathrm{p}<0.001$ ). A PLR higher than 112 had 83\% sensitivity and $52 \%$ specificity in predicting mortal cases (AUC:0.76, $p<0.001$ ). Figure 1 shows the ROC curves of CRP, NLR, and PLR.

PLR was significantly and positively correlated with CRP levels $(\mathrm{r}=0.28, \mathrm{p}<0.001)$. Similarly, NLR was also significantly and positively correlated with CRP levels $(\mathrm{r}=0.29, \mathrm{p}<0.001)$. 


\section{DISCUSSION}

The results of the present study showed that the elevation of both PLR and NLR was associated with mortality in intensive care patients. Moreover, PLR and NLR were better than CRP in predicting mortality. Finally, both PLR and NLR were significantly correlated with serum CRP levels.

The proportion of NLR to lymphocyte count, namely NLR, can be used as an inflammatory marker in intensive care practice since the physiologic response of circulating leukocytes to inflammatory stress cause an elevation in neutrophil count and decrement in lymphocyte count ${ }^{9}$. Activated neutrophils secrete enzymes such as acid phosphatase, myeloperoxidase, and elastase, which cause tissue destruction $^{10}$. Thus, NLR is proposed as a marker that reflects the inflammatory burden by elevated neutrophil count and indicates physiological stress and poor health condition by decreased lymphocyte count $^{11}$. Indeed, mortality due to coronary heart disease increased with higher NLR levels in studies in the literature ${ }^{12,13}$.

The NLR has been introduced as a simple but effective marker of inflammatory condition, since it was found to be correlated with the severity and prognosis of the subjects with sepsis when compared and evaluated along with prognostic scores, such as APACHE 2 (Acute Physiology and Chronic Health Evaluation II) and SOFA (Sepsis-related Organ Failure Assessment ${ }^{14}$. Similar to the knowledge found in the literature, the present study suggests that NLR could serve as a prognostic factor in the ICU population.

The association between PLR and inflammatory conditions is relatively a more recent finding then the association between inflammation and NLR. Besides NLR, PLR also predicted the prognosis of subjects with hepatic cancer ${ }^{15}$. In another study from 2014, authors reported that both NLR and PLR elevated with the increasing stage of ovarian carci- nomas ${ }^{16}$. Moreover, it was found that NLR and PLR were higher in subjects with non-dipper hypertension compared with patients with dipper hypertension $^{17}$. Shimoyama et al. ${ }^{18}$ proposed that NLR and PLR were better than all other inflammation-related prognostic scores in predicting outcomes of subjects with gastrointestinal perforation. NLR and PLR were suggested as reliable prognostic indexes in renal cell carcinoma $^{19}$, in advanced pancreas carcinoma ${ }^{20}$, in mesenteric arterial embolism and thrombosis ${ }^{21}$, and in the severity of gallstone pancreatitis ${ }^{22}$. Qi et al. ${ }^{23}$ reported that PLR was an independent prognostic marker for survival in melanoma patients in a recently published study. The results of the present study emphasize the significant association between mortality of ICU subjects and elevated PLR suggested by the data in the literature.

Even though CRP is the most important and commonly used inflammatory marker in clinical practice, our results show that both PLR and NLR predicted mortality better than CRP. This is an outstanding result which could add a lot to current literature knowledge.

The inevitable limitation of our study is its retrospective design, which could cause selection bias. Another limitation could be the relatively small study population. However, the results of the present study found a significant association between the prognosis of ICU subjects and PLR and NLR and a significant correlation between CRP and both NLR and PLR.

\section{CONCLUSION}

We suggest that automatic blood count devices should be arranged to calculate PLR and NLR levels since higher PLR and NLR levels predict increased mortality in the ICU population. We also suggest that physicians should pay particular attention in the treatment of patients in ICU with elevated NLR and PLR.

\section{RESUMO}

OBJETIVO: Pacientes em unidades de terapia intensiva (UTI) apresentam maior morbimortalidade. Nosso objetivo foi estudar a razão de neutrófilos para linfócitos (NLR) e de plaquetas para linfócitos $(P L R)$ na população de UTI.

MÉTODOS: Dados médicos e laboratoriais dos pacientes tratados em UTI foram analisados retrospectivamente. Os pacientes foram divididos em grupos de falecidos e de sobreviventes.

RESULTADOS: O NLR de indivíduos sobreviventes e falecidos foi de 3,6 (0,2-31) e 9,5 (1-40), respectivamente ( $p<0,001)$. A $P L R$ dos pacientes sobreviventes (111 [16-537]) foi significativamente menor do que a PLR do grupo dos falecidos (209 [52-1143]), ( $p<0,001)$. Uma RNL maior que 4,9 teve $84 \%$ de sensibilidade e $67 \%$ de especificidade na previsão de casos mortais. (AUC: 0,80, $p<0,001$ ). Uma PLR 
superior a 112 apresentou sensibilidade de $83 \%$ e especificidade de 52\% na previsão de casos mortais (AUC: 0,76, p <0,001). Ambos, $P L R$ e NLR, foram significativamente e positivamente correlacionados com os níveis de proteína reativa c.

CONCLUSÃo: Sugerimos que os médicos prestem atenção especial ao tratamento de pacientes em UTI com valores elevados de RNL e RPL.

PALAVRAS-ChaVe: Cuidados críticos. Neutrófilos. Linfócitos. Plaquetas. Mortalidade.

\section{REFERENCES}

1. Balcan B, Olgun S, Torlak F, Sagmen SB, Eryüksel E, Karakurt S. Determination of factors affecting mortality of patients with sepsis in a tertiary intensive care unit. Turk Thorac ). 2015;16(3):128-32.

2. Aktas G, Sit M, Tekce H, Alcelik A, Savli H, Simsek T, et al. Mean platelet volume in nasal polyps. West Ind Med J. 2013;62(6):515-8.

3. Aktas G, Sit M, Dikbas O, Tekce BK, Savli H, Tekce H, et al. Could red cell distribution width be a marker in Hashimoto's thyroiditis? Exp Clin Endocrinol Diabetes. 2014;122(10):572-4.

4. Aktas G, Sit M, Karagoz I, Erkus E, Ozer B, Kocak MZ, et al. Could red cell distribution width be a marker of thyroid cancer? I Coll Physicians Surg Pak. 2017;27(9):556-8.

5. Kapsoritakis AN, Koukourakis MI, Sfiridaki A, Potamianos SP, Kosmadaki MG, Koutroubakis IE, et al. Mean platelet volume: a useful marker of inflammatory bowel disease activity. Am | Gastroenterol. 2001;96(3):776-81.

6. Aktas G, Sit M, Dikbas O, Erkol H, Altinordu R, Erkus E, et al. Elevated neutrophil-to-lymphocyte ratio in the diagnosis of Hashimoto's thyroiditis. Rev Assoc Med Bras. 2017;63(12):1065-8.

7. Salciccioli JD, Marshall DC, Pimentel MA, Santos MD, Pollard T, Celi LA, et al. The association between the neutrophil-to-lymphocyte ratio and mortality in critical illness: an observational cohort study. Crit Care. 2015;19:13.

8. Yoldas H, Karagoz I, Ogun MN, Velioglu Y, Yildiz I, Bilgi M, et al. Novel mortality markers for critically ill patients. I Intensive Care Med. 2018:885066617753389.

9. Jilma B, Blann A, Pernerstorfer T, Stohlawetz P, Eichler HG, Vondrovec B, et al. Regulation of adhesion molecules during human endotoxemia. No acute effects of aspirin. Am J Resp Crit Care Med. 1999;159(3):857-63.

10. Reichlin T, Socrates T, Egli P, Potocki M, Breidthardt T, Arenja N, et al. Use of myeloperoxidase for risk stratification in acute heart failure. Clin Chem. 2010;56(6):944-51.

11. Yamanaka T, Matsumoto S, Teramukai S, Ishiwata R, Nagai Y, Fukushima M. The baseline ratio of neutrophils to lymphocytes is associated with patient prognosis in advanced gastric cancer. Oncology. 2007;73(3-4):21520.

12. Tamhane UU, Aneja S, Montgomery D, Rogers EK, Eagle KA, Gurm HS. Association between admission neutrophil to lymphocyte ratio and outcomes in patients with acute coronary syndrome. Am J Cardiol. 2008;102(6):653-7.
13. Duffy BK, Gurm HS, Rajagopal V, Gupta R, Ellis SG, Bhatt DL. Usefulness of an elevated neutrophil to lymphocyte ratio in predicting longterm mortality after percutaneous coronary intervention. Am J Cardiol. 2006;97(7):993-6.

14. Yilmaz H, Cakmak M, Inan O, Darcin T, Akcay A. Can neutrophil-lymphocyte ratio be independent risk factor for predicting acute kidney injury in patients with severe sepsis? Ren Fail. 2015;37(2):225-9.

15. Li C, Wen TF, Yan LN, Li B, Wang WT, Yang JY, et al. Postoperative neutrophil-to-lymphocyte ratio plus platelet-to-lymphocyte ratio predicts the outcomes of hepatocellular carcinoma. J Surg Res. 2015;198(1):73-9.

16. Kokcu A, Kurtoglu E, Celik H, Tosun M, Malatyalıoglu E, Ozdemir AZ. May the platelet to lymphocyte ratio be a prognostic factor for epithelial ovarian cancer? Asian Pac J Cancer Prev. 2014;15(22):9781-4.

17. Sunbul M, Gerin F, Durmus E, Kivrak T, Sari I, Tigen K, et al. Neutrophil to lymphocyte and platelet to lymphocyte ratio in patients with dipper versus non-dipper hypertension. Clin Exp Hypertens. 2014;36(4):217-21.

18. Shimoyama $Y$, Umegaki $O$, Agui T, Kadono N, Minami T. Neutrophil to lymphocyte ratio and platelet to lymphocyte ratio are superior to other inflammation-based prognostic scores in predicting the mortality of patients with gastrointestinal perforation. A Clin Rep. 2017;3(1):49.

19. Semeniuk-Wojtas A, Lubas A, Stec R, Syrylo T, Niemczyk S, Szczylik C. Neutrophil-to-lymphocyte ratio, platelet-to-lymphocyte ratio, and C-reactive protein as new and simple prognostic factors in patients with metastatic renal cell cancer treated with tyrosine kinase inhibitors: a systemic review and meta-analysis. Clin Genitourin Cancer. 2018;16(3):e685-93.

20. Lee BM, Chung SY, Chang IS, Lee KJ, Seong |. The neutrophil-lymphocyte ratio and platelet-lymphocyte ratio are prognostic factors in patients with locally advanced pancreatic cancer treated with chemoradiotherapy. Gut Liver. 2018;12(3):342-52.

21. Wang $S$, Liu H, Wang $Q$, Cheng Z, Sun S, Zhang Y, et al. Neutrophil-to-lymphocyte ratio and platelet-to-lymphocyte ratio are effective predictors of prognosis in patients with acute mesenteric arterial embolism and thrombosis. Ann Vasc Surg. 2018;pii:S0890-5096.

22. Cho SK, Jung S, Lee KJ, Kim JW. Neutrophil to lymphocyte ratio and platelet to lymphocyte ratio can predict the severity of gallstone pancreatitis. BMC Gastroenterol. 2018;18(1):18.

23. Qi Y, Zhang Y, Fu X, Wang A, Yang Y, Shang Y, et al. Platelet-to-lymphocyte ratio in peripheral blood: a novel independent prognostic factor in patients with melanoma. Int Immunopharmacol. 2018;56:143-7. 